\title{
Exploitation of heterosis for simultaneous improvement in both grain and stover yields of arid zone pearl millet (Pennisetum glaucum (L.) R. Br.)
}

\author{
F.R. Bidinger ${ }^{\mathrm{a},{ }^{*}}$, O.P. Yadav ${ }^{\mathrm{b}}$, M.M. Sharma ${ }^{\mathrm{a}}$, E.J. van Oosterom ${ }^{\mathrm{a}, 1}$, Y.P. Yadav ${ }^{\mathrm{c}}$ \\ anternational Crops Research Institute for the Semi-Arid Tropics, Patancheru 502 034, Andhra Pradesh, India \\ ${ }^{\mathrm{b}}$ Central Arid Zone Research Institute, Jodhpur 342 003, Rajasthan, India \\ ${ }^{\mathrm{c}}$ C.S.S. Haryana Agricultural University, Bawal 123 501, Haryana, India
}

Received 2 May 2002; received in revised form 5 December 2002; accepted 8 January 2003

\begin{abstract}
The requirement for simultaneous increases in stover as well as grain yields in pearl millet in arid zone environments means that conventional selection for grain yield improvement through increased harvest index (HI) is not applicable to such environments. In addition, there is a need to retain the adaptive traits present in local landrace germplasm, so that new cultivars for the arid zone do not trade increased productivity for reduced yield stability and increased risk of crop failure. This research was designed to test the hypothesis that it will be possible to meet these requirements by exploiting heterosis for overall biomass production in topcross hybrids (TCH) made with adapted, landrace-derived pollinators and dual purpose male-sterile seed parents, which partition the extra biomass of their hybrids equally to grain and stover. General combining ability (GCA) estimates for seven landrace-derived populations/varieties, derived from multi-environment tests in arid zone environments, indicated that selection history played a large role in determining GCA for both biomass and HI, with prior selection (for grain yield) favoring GCA for HI at the expense of GCA for biomass. A similar analysis of a set of male-sterile seed parents indicated a wide range of GCA for both grain and stover yields, with a similar tradeoff of GCA for one trait against GCA for the other. It was, however, possible to identify several parental lines with a positive GCA for biomass, achieved by a positive GCA for growth rate, and neutral GCA for HI, resulting in positive/ neutral GCA for both stover and grain yields. A limited test of the ability of parental GCA to predict heterosis in TCH indicated that heterosis for stover yield was closely related to pollinator GCA for stover yield, and heterosis for grain yield was related to both pollinator and A-line GCA for HI. The same test confirmed the original hypothesis that crosses of parents with positive GCA for biomass/growth rate and neutral GCA for HI could produce $\mathrm{TCH}$ with positive heterosis for grain yield without an off-setting negative heterosis for stover yield. The frequency of such parental lines was limited, however.
\end{abstract}

(C) 2003 Elsevier Science B.V. All rights reserved.

Keywords: Arid zone; General combining ability; Heterosis; Pennisetum glaucum; Topcross hybrids

Abbreviations: GCA, general combining ability; HI, harvest index; MS, mean square; MSE, mean square error; $\mathrm{TCH}$, topcross hybrid

*Corresponding author. Fax: +91-40-23241239. E-mail address: f.bidinger@ cgiar.org (F.R. Bidinger).

${ }^{1}$ Present address: School of Land and Food Sciences, University of Queensland, Brisbane, Qld 4072, Australia.

\section{Introduction}

Pearl millet (Pennisetum glaucum (L.) R. Br.) is the staple cereal in arid and drier semi-arid regions of south Asia, primarily because it is the only cereal crop that is capable of producing a reliable yield under the 
marginal growing conditions of these regions (Bidinger and Hash, 2003). Its grain forms the basis of the diet of human populations in these regions and the stover forms the principal maintenance ration for ruminant livestock during the dry season. Farmers in the arid zone (the western districts of the state of Rajasthan, India, with mean annual rainfall $<300 \mathrm{~mm}$ ) primarily grow traditional landrace cultivars, which are considered to have evolved a high degree of adaptation to the various environmental stresses that characterize arid zone environments (Kelley et al., 1996). These stresses are mainly a consequence of frequent droughts of unpredictable intensity and duration (Sastri et al., 1982; van Oosterom et al., 1996), which are compounded by high evaporation rates and high soil and air temperatures, and by the low levels of native fertility and limited water holding capacity of most arid zone soils. Adaptation to the stresses of arid zone environments is generally the primary requirement for new cultivars for arid zone crops (Ceccarelli, 1994), including pearl millet in the south Asian arid zone (Yadav and Weltzien R., 2000). At the same time, however, cultivars with increased potential grain and stover productivity are necessary to support growing populations and to provide an incentive to farmers to attempt even modest increases in inputs in their farming systems.

Improvement in grain yield in most crop plants has been achieved by selection for greater partitioning to grain, but with little increase in total biomass, resulting in a tradeoff in grain and stover productivity in modern cultivars (e.g. Austin et al., 1993). This strategy for increasing grain yield is less applicable for marginal environments than it is for favorable ones, for several reasons: (1) In areas where animal population densities are high and native pasture can no longer support the existing animal numbers throughout the dry season, such as the arid zone of NW India, millet stover for fodder can be equally important as grain (Kelley et al., 1996). (2) Traditional adaptive mechanisms in marginal environments, such as deep rooting, asynchronous tiller development, maintenance of stem carbohydrate reserves, etc., likely involve the partitioning of significant amounts of biomass to vegetative tissues (Bidinger and Hash, 2003). (3) The addition of even very modest amounts of organic matter to the soil, by the direct or indirect (via animal manure) return of crop residues, is essential to the maintenance of soil fertility in many arid zone soils (e.g. Agarwal et al., 1997).
Therefore the improvement in grain yield (needed to support growing human populations) should not be at the cost of decreased stover production; total biomass productivity needs to be increased as well.

Genetic studies suggest that the improvement of biomass productivity by conventional plant breeding, without extending crop duration, is likely to be slow, especially under marginal conditions. Growth rate/ biomass productivity in pearl millet appears to be governed mainly by non-additive gene effects (Lynch et al., 1995; Gupta and Phul, 1981), and heritabilities for biomass productivity are modest (Rattunde et al., 1989). For example, Rattunde and Witcombe (1993) reported average gains in biomass after three to four cycles of recurrent selection for improved grain yield in four populations of $8.5 \%$ per cycle, measured under irrigated conditions, but only $2.3 \%$ per cycle measured under terminal stress conditions. These increases translated to a $5.7 \%$ gain per cycle in grain yield and a $1.7 \%$ in stover yield under favorable condition, and a $2.5 \%$ gain in grain yield and $0.5 \%$ gain in stover yield per cycle under stress conditions. Such results would be expected physiologically, as growth rate or biomass productivity is a not a simple genetic trait, but the result of the interaction of many underlying, complex factors (canopy development, radiation interception, radiation use efficiency, respiration rate, etc.). The varying effects of stress on the individual components of overall biomass productivity further complicate attempts at genetic improvement of biomass productivity in marginal environments.

The more effective and rapid way to improve biomass yield in pearl millet is likely to be by exploiting heterosis in F1 hybrids (Hanna and Gupta, 1999). Heterosis in pearl millet is well documented for both overall biomass (e.g. Burton, 1968), and for various components of biomass productivity (Virk, 1988), from studies comparing hybrids and inbred parental lines. However, there are very few studies in pearl millet evaluating heterosis for biomass in hybrids made with open-pollinated parents (which are not affected by inbreeding depression), which is the relevant comparison for the question of increasing grain and stover productivity over the levels currently available in farmers' open-pollinated cultivars. Yadav et al. (2000) reported an average of $15 \%$ heterosis (compared to the open-pollinated pollinator parent) in growth rate (biomass per day) in topcross hybrids 
(TCH) based on unimproved landrace pollinators, which translated to a positive biomass heterosis where crop duration of the hybrid equaled that of the pollinator. The partitioning of this extra biomass to either grain or fodder appeared to be controlled by the harvest index (HI) of the seed parent, resulting in differential heterosis for either grain or stover yields, depending upon the seed parent used.

Bidinger et al. (1994) and Yadav et al. (2000) suggested that it may be possible to meet farmers' needs for increased grain and stover production, while retaining critical adaptation to arid zone environments, by exploiting heterosis between locally adapted landraces and male-sterile seed parents that partition the extra dry matter to both grain and stover. TCH (inbred male-sterile seed parent $\times$ open-pollinated variety pollinator) appear to be a viable cultivar type in pearl millet, and have various advantages over conventional single cross-hybrids in the form of easier hybrid seed production and likely greater stability of both yield and disease resistance (Talukdar et al., 1996). In addition, the use of landrace-derived variety pollinators should help provide TCH targeted to the arid zone with the needed adaptation to the stresses of these environments (Bidinger et al., 1994). The objective of the research reported in this paper was to test the hypothesis that it should be possible to produce TCH meeting farmers' requirements, if it were possible to identify (1) landrace-based pollinator populations with a high positive general combining ability (GCA) for total biomass productivity, and (2) seed parents with non-negative combining ability for both biomass and HI. This hypothesis was tested by: (1) assessing general combining abilities for biomass, grain and stover production of a broad set of landrace-based pollinators and male-sterile seed parents, to determine if the desired parental types could be identified and (2) measuring grain and stover heterosis in a smaller set of TCH made with parents with varying general combining abilities for these traits.

\section{Materials and methods}

\subsection{Genetic materials}

A set of 49 test crosses was made by manually crossing each of seven phenotypically diverse male- sterile seed parents (A-lines) with seven variable landrace pollinators, chosen to represent a gradient from an unimproved landrace to an elite restorer composite (Table 1). The A-lines chosen represent a broad range of plant types (Table 1). Grain types are generally early flowering, with a high degree of partitioning of biomass to grain; dual purpose and landrace plant types are generally longer duration, produce higher total amounts of biomass and partition this more equally to grain and fodder. The grain types were bred from primarily Indian germplasm; the dual purpose types were bred from both Indian and West African parents. Except for 843A, all A-lines were bred by the ICRISAT program at Patancheru, India.

Three of the pollinators (Nokha Local, Barmer population and ICMV 94888) represent unimproved (by progeny-based population improvement methods) primarily landrace germplasm, but each of these had a different history of selection of the original genetic material on which they were based. Nokha Local is a pure farmer landrace cultivar, maintained by a farmer from Khichiyasar village in Bikaner district in western Rajasthan. The Barmer population was formed by inter-mating five superior, but unimproved landrace accessions of the Barmer type from the ICRISAT genebank (Yadav and Weltzien R., 1998). ICMV 94888 was created by inter-mating 68 visually selected S2 progenies derived from a population cross between a central Rajasthan landrace and an improved, dual purpose variety (Yadav and Weltzien R., 1998). The pollinator set also included three improved open-pollinated varieties/populationsCZ-IC 311, ERajPop and WRajPop. CZ-IC 311 is a variety based on 16 full sib progenies selected from the improved Dual Purpose Pakistan Population, which was made by random-mating 100 dual purpose landrace accessions from Pakistan (Yadav and Weltzien R., 1998). ERajPop and WRajPop were originally made from a small number of carefully selected landrace accessions from Rajasthan, with WRajPop (Western Rajasthan Population) having a geographic focus and ERajPop (Early Rajasthan Population) having a maturity focus (Yadav and Weltzien R., 1998). Improvement in all three base populations was by three to four cycles of full-sib progeny-based recurrent selection for grain yield and disease resistance. Improvement involved making $300-400$ full-sib progenies during the dry season at 
Table 1

Description and pedigree/origin details of male-sterile lines and pollinator populations used in study of combining ability for grain and stover yields $^{\mathrm{a}}$

\begin{tabular}{|c|c|c|}
\hline Parent & Description & Origin or pedigree \\
\hline \multicolumn{3}{|l|}{ Male-sterile lines } \\
\hline ICMA 91444 & Landrace plant type, named A-line & {$[843 \mathrm{~B} \times($ Boudema-481 $\times$ Ankoutess- 2$)-4]-2$} \\
\hline ICMA 89111 & Dual purpose plant type, named A-line & {$[843 \mathrm{~B} \times($ Gero New Strain $\times$ Saria Synthetic $) 48-40-4]-30-B-B-1$} \\
\hline ICMA 94444 & Dual purpose plant type, named A-line & $(843 \mathrm{~B} \times 405 \mathrm{~B})-4-\mathrm{B}$ \\
\hline $841 \mathrm{~A}$ & Intermediate plant type, released A-line & Downy mildew resistant selection from unknown outcross of 5141A \\
\hline ICMA 93333 & Intermediate plant type, named A-line & $(843 \mathrm{~B} \times$ ICMPS 900-9-8-3-2)21-8-4 \\
\hline $843 \mathrm{~A}$ & Grain plant type, released A-line & $\begin{array}{l}\text { Early flowering dwarf male-sterile line bred at } \\
\text { Kansas State University, USA }\end{array}$ \\
\hline ICMA 94111 & Grain plant type, named A-line & $\begin{array}{l}{[(\mathrm{ICMB} 89111 \times \mathrm{ICMB} 88001) \times\{(81 \mathrm{~B} \times \mathrm{SRL} 53-1) \times 843 \mathrm{~B}\}-} \\
3+\times \mathrm{IP} 9402-2+)]-31\end{array}$ \\
\hline \multicolumn{3}{|l|}{ Pollinators } \\
\hline Nokha local & Unimproved landrace population & $\begin{array}{l}\text { Collected from the village of Khichiyasar in Bikaner district of } \\
\text { Rajasthan }\end{array}$ \\
\hline BarmerPop & $\begin{array}{l}\text { Unimproved population of pure } \\
\text { landrace origin }\end{array}$ & $\begin{array}{l}\text { Bred by inter-mating five selected, typical landraces from the Barmer } \\
\text { district of Rajasthan }\end{array}$ \\
\hline ICMV 94888 & $\begin{array}{l}\text { Unimproved population of } \\
\text { landrace } \times \text { improved variety origin }\end{array}$ & $\begin{array}{l}\text { Bred by random mating } 68 \mathrm{~S} 2 \text { progenies from a population cross of the } \\
\text { landrace IP } 3201 \times \text { the improved variety ICMV } 84400\end{array}$ \\
\hline CZ-IC 311 & Improved variety of mainly landrace origin & $\begin{array}{l}\text { Bred by inter-mating } 16 \text { full sib progenies selected from progeny trial } \\
\text { of the Dual Purpose Pakistan Population }\end{array}$ \\
\hline WRajPop & Improved population of landrace origin & $\begin{array}{l}\text { Bred from } 13 \text { selected, representative landrace accessions from North- } \\
\text { western India and improved by several cycles of recurrent selection }\end{array}$ \\
\hline ERajPop & Improved population of landrace origin & $\begin{array}{l}\text { Bred from } 30 \mathrm{~S} 1 \text { progenies from four early maturing landraces from } \\
\text { Rajasthan and improved by several cycles of recurrent selection }\end{array}$ \\
\hline HiTiP 88 & $\begin{array}{l}\text { Improved population of } \\
\text { non-landrace origin }\end{array}$ & $\begin{array}{l}\text { Bred from } 13 \text { high tillering inbred lines from the ICRISAT pollinator } \\
\text { collection and improved by several cycles of recurrent selection }\end{array}$ \\
\hline
\end{tabular}

${ }^{\text {a }}$ All parents were bred at ICRISAT unless otherwise noted.

ICRISAT, evaluating them at three to four locations in Rajasthan during the rainy season, selecting the highest yielding $20 \%$ progenies, and inter-mating them using remnant seed. Finally, the pollinator set included one non-landrace population-HiTiP 88 (High Tillering Population 1988) which was made by random-mating a number of early maturing, elite inbred pollinators with a high tillering plant type (Yadav and Weltzien R., 1998).

\subsection{Field experiments}

The main experiment-the 7 pollinator $\times 7$ A-line testcross hybrid set-was first grown during the rainy season (June to October) of 1995 at the Central Arid Zone Research Institute (CAZRI), Jodhpur $\left(26^{\circ} 18^{\prime} \mathrm{N}\right)$, and the Rajasthan Agricultural University (RAU), Agricultural Research Station, Fatehpur $\left(27^{\circ} 17^{\prime} \mathrm{N}\right)$. It was repeated during the rainy season of 1999 at the Haryana Agricultural University Regional Research Station, Bawal $\left(28^{\circ} 12^{\prime}\right)$, the RAU Agricultural Research Station, Mandor $\left(26^{\circ} 21^{\prime} \mathrm{N}\right)$, and CAZRI, Jodhpur. The 1995 data were part of a larger A-line $\times$ pollinator evaluation $(12$ A-lines $\times$ the 7 pollinators). The 1999 experiment involved just the selected 49 testcrosses, and was conducted in order to obtain a better estimate (based on more environments) of the GCA of selected seed parents for biomass, HI and grain and stover yields.

A smaller experiment consisting of three selected pollinators (Nokha local, CZ-IC 311 and WRajPop) $\times$ three selected A-lines (843A, ICMA 93333, and ICMA 94444) from the full $7 \times 7$ set was grown at CAZRI, Jodhpur, and RAU, Fatehpur, in 1996. This experiment also included the three pollinator populations themselves, in order to estimate heterosis (compared to the open-pollinated pollinator population) in each of the nine $\mathrm{TCH}$. This experiment provided an 
independent data set from which to estimate the effectiveness of the estimates of GCA derived from the 1995 and 1999 experiments in predicting heterosis for grain and stover yields in the set of nine $\mathrm{TCH}$.

At all locations, experiments were carried out under rainfed conditions, with sowing done with a two-row plot planter after the receipt of first sowing rain $(>25 \mathrm{~mm}$ ) of the season. Testcrosses were evaluated in a randomized block design with two replications in 1995, and in an incomplete lattice design with three replications in 1999. The smaller 1996 trials were conducted in a randomized block design with three replications. The plot size for each hybrid was 2 rows of $4 \mathrm{~m}$ length spaced $0.60 \mathrm{~m}$ apart in 1995 and 1999, and 4 rows $\times 4 \mathrm{~m} \times 0.6 \mathrm{~m}$ in 1996. A plant-to-plant spacing of approximately $30 \mathrm{~cm}$ was maintained within rows, by over sowing and hand thinning the plots 2-3 weeks after sowing. Soils were sandy to loamy sand, with moderate fertility levels. The crop was fertilized with $18 \mathrm{~kg} \mathrm{~N} \mathrm{ha}^{-1}$ and $20 \mathrm{~kg} \mathrm{Pha}^{-1}$, broadcast and incorporated prior to planting, plus $20 \mathrm{~kg} \mathrm{~N} \mathrm{ha}^{-1}$ side dressed between 3 and 4 weeks after sowing, following a rain.

Flowering time was recorded as the number of days from sowing to the emergence of the stigmas in the main shoot panicles of $50 \%$ of the plants in a plot. Productive panicles from the center $3 \mathrm{~m}$ of both rows (from the two center rows in 1996) were harvested at maturity, counted and weighed after sun drying for 10-15 days. The dried panicles were mechanically threshed and the grain weighed. The stover from the same harvest area was cut, and the stover fresh weight per plot recorded. A subsample was chopped, its fresh weight recorded, sun dried for 10-15 days and reweighed to estimate moisture percentage in the stover at harvest. Stover dry weight per plot was estimated from the fresh weight of the stover at harvest and the moisture percentage of the subsample. Stover and panicle dry weights were added to obtain biomass yield, and all plot yields were converted to $\mathrm{g} \mathrm{m}^{-2}$ field-dry mass. HI was calculated as the ratio of grain yield to biomass yield and expressed as a percentage. Growth rate was estimated as stover yield/ (flowering +10 days), in order to remove the effects of differences in maturity on differences in dry mass productivity (Bramel-Cox et al., 1984). Growth rate was based on vegetative biomass, rather than total biomass, to remove effects of sink size differences (which can affect total biomass) among testcrosses on growth rate.

Seasonal rainfall, which is the major variable affecting productivity of adequately fertilized trials in the arid zone, ranged from $151 \mathrm{~mm}$ (Mandor 1999) to $383 \mathrm{~mm}$ (Bawal 1999) across test environments during the 1995 and 1999 growing seasons (Table 2). In most of the test environments, except Mandor 1999, pre-flowering rainfall was generally adequate; the main difference among environments was post-flowering rainfall, which ranged from virtual nil in Jodhpur in both years and Mandor in 1999 to $100 \mathrm{~mm}$ in Bawal in 1999.

\subsection{Data analysis}

Combined analysis of variance (ANOVA) for the five 1995/1999 environments was performed using the ANOVA procedure of SAS, with replication nested within test environment. Testcross and testcross $\times$ environment sums of squares were partitioned into effects of A-line, pollinator and their interaction. The effects of landraces and male-sterile lines and their interactions were determined following the line $x$ tester analysis of Kempthorne (1957), assuming the following model:

$$
\begin{aligned}
Y_{i j k}= & \mu+g_{i}+g_{j}+s_{i j}+e_{k}+(g e)_{i k}+(g e)_{j k} \\
& +(s e)_{i j k}+\delta_{i j k}
\end{aligned}
$$

where $Y_{i j k}$ is the performance of the hybrid, made with $i$ th A-line and $j$ th pollinator, in the $k$ th environment; $\mu$ is the overall mean; $g_{i}$ the effect of $i$ th A-line; $g_{j}$ the effect of $j$ th pollinator; $s_{i j}$ the interaction of the $i$ th Aline and the $j$ th pollinator; $e_{k}$ the effect of the $k$ th environment; $(g e)_{i k}$ the interaction of $g_{i}$ and $e_{k} ;(g e)_{j k}$ the interaction of $g_{j}$ and $e_{k}$; and $(s e)_{i j k}$ the interaction of $s_{i j}$ and $e_{k}$.

Mean squares for all sources of variation in the ANOVA were significant for all variables reported, but the relative importance of different sources of variation differed considerably. In order to assess the importance of individual sources of variation, variance components were estimated by the variance component procedure of Genstat, from the combined analysis of the five test environments, with all effects assumed to be random. Percentage variation accounted for by each source of variation was estimated from the ratio 
Table 2

Pre- and post-flowering rainfall received and trial average biomass, HI, grain and stover yields for the $7 \times 7$ A-line $\times$ pollinator testcross trial grown in five test environments in 1995/1999, and for the comparison of three pollinators and their testcrosses on three A-lines grown in two environments in $1996^{\mathrm{a}}$

\begin{tabular}{|c|c|c|c|c|c|c|}
\hline \multirow[t]{2}{*}{ Location/Year } & \multicolumn{2}{|l|}{ Rainfall (mm) } & \multirow{2}{*}{$\begin{array}{l}\text { Biomass yield } \\
\left(\mathrm{g} \mathrm{m}^{-2}\right)\end{array}$} & \multirow[t]{2}{*}{ HI (\%) } & \multirow{2}{*}{$\begin{array}{l}\text { Grain yield } \\
\left(\mathrm{g} \mathrm{m}^{-2}\right)\end{array}$} & \multirow{2}{*}{$\begin{array}{l}\text { Stover yield } \\
\left(\mathrm{g} \mathrm{m}^{-2}\right)\end{array}$} \\
\hline & Pre-flowering & Post-flowering & & & & \\
\hline Fatehpur 1995 & 260.1 & 18.3 & - & - & 189 & - \\
\hline Jodhpur 1995 & 299.9 & 4.5 & 418 & 32.1 & 137 & 212 \\
\hline Bawal 1999 & 282.6 & 100.2 & 832 & 23.9 & 195 & 531 \\
\hline Mandor 1999 & 139.6 & 11.2 & 164 & 22.9 & 38 & 106 \\
\hline Jodhpur 1999 & 195.7 & 9.4 & 186 & 28.6 & 54 & 108 \\
\hline Mean & & & 424 & 26.0 & 116 & 260 \\
\hline S.E. & & & \pm 20.9 & \pm 1.08 & \pm 7.8 & \pm 13.7 \\
\hline Heritability & & & 0.22 & 0.79 & 0.18 & 0.34 \\
\hline Jodhpur 1996 & 344.8 & 79.0 & 756 & 27.0 & 205 & 474 \\
\hline Fatehpur 1996 & 195.0 & 156.2 & 1237 & 24.5 & 298 & 818 \\
\hline Mean & & & 1001 & 25.8 & 251 & 646 \\
\hline S.E. & & & 102.9 & 1.05 & 26.8 & 69.1 \\
\hline Heritability & & & 0.13 & 0.87 & 0.29 & 0.49 \\
\hline
\end{tabular}

${ }^{\text {a }}$ Entry mean heritabilities were calculated as the ratio of $\sigma_{g}^{2}$ to $\left(\sigma_{g}^{2}+\sigma_{g e}^{2} / e+\sigma_{E}^{2} / r e\right)$, where $e$ is the number of environments and $r$ the number of replications in the data set.

of the variance component for that source to the sum of the variance components for all sources (excluding the residual). GCA for each parental line was estimated as the mean of all crosses involving that parent minus the overall mean. Significance of the parental GCA was determined by $t$-test, with 77 d.f. (error d.f.), where $t=\mathrm{GCA} /[\sqrt{(\mathrm{MSE} /(r p))}], r$ is the total number of replications, across environments (11) and $p$ is the number of tester parents (7).

Stepwise regressions were run on parental GCA for grain and stover yield to better understand the relationships among these and GCA for time to flowering, biomass, HI and vegetative growth rate, using the REGR procedure of SAS.

Data from the smaller 1996 experiment was analyzed across the two test environments using the ANOVA procedure of SAS, with replication within environment. Percent heterosis for individual TCH was calculated as the superiority of individual TCH over their landrace pollinators (equivalent to high parent heterosis). This procedure was used for two reasons: (i) to avoid inflating heterosis values by including inbred A-line values in the calculations, as pearl millet suffers from inbreeding depression, and (ii) to specifically address the objective of exploiting heterosis to increase yields of adapted landrace cultivars/populations (Yadav et al., 2000). The ability of the parental GCA for grain and stover yield to predict grain and stover yield heterosis in the 1996 trials was tested by regressing 1996 heterosis data on the parental GCA for grain and stover yield and comparing actual to predicted heterosis. In addition, stepwise regressions were used to evaluate the relative importance of parental GCA for biomass productivity, growth rate, time to flowering and $\mathrm{HI}$ on hybrid grain and stover yield heterosis.

\section{Results}

\subsection{Environment and genotype effects, 1995/1999}

Trial mean biomass productivity varied from $164 \mathrm{~g} \mathrm{~m}^{-2}$ (Mandor 1999) to $832 \mathrm{~g} \mathrm{~m}^{-2}$ (Bawal 1999-Table 2). Biomass productivity was influenced by the amount of post-flowering moisture available, either the actual post-flowering rainfall (e.g. Bawal 1999 ) or stored soil moisture from abundant preflowering rainfall (e.g. Jodhpur 1995). Mean trial HI was relatively less affected by rainfall differences than was biomass productivity, varying only between 23 to $32 \%$. As a consequence, variation in grain yield 
mainly followed variation in biomass productivity, ranging from a low of $38 \mathrm{~g} \mathrm{~m}^{-2}$ at Mandor 1999 to $195 \mathrm{~g} \mathrm{~m}^{-2}$ at Bawal 1999 (Table 2).

The MS for environment were highly significant for all traits measured (ANOVA, data not presented). Environment (E) accounted for more than $80 \%$ of total variation in the data set, for all traits except $\mathrm{HI}$ (44\%) (Table 3). Genotype (testcross) MS were also highly significant for all variables measured (ANOVA, data not presented), but genotype (G) variance accounted for a very small (and often non-significant) fraction of the total variance for all traits, except HI (Table 3). Genotype differences were significantly influenced by environment, as the MS for $\mathrm{G} \times \mathrm{E}$ were also significant for all traits measured (ANOVA, data not presented), and $G \times E$ variances were significant for all traits (Table 3). $\mathrm{G} \times \mathrm{E}$ effects accounted for a greater fraction of the total variance $(8-17 \%$ of total experimental variance) for time to flower, grain yield, stover yield and biomass yield than did $\mathrm{G}$ effects $(<1-$ $4 \%$ ). The only exception to this pattern was HI, where $\mathrm{G}$ and $\mathrm{G} \times \mathrm{E}$ effects accounted for significant and similar proportions of the total variance (29 and $24 \%$, respectively). In contrast to the case of HI, genetic variance for biomass represented less than $1 \%$ of the total variance for this trait, and $\mathrm{G} \times \mathrm{E}$ variance only $14 \%$ of the total variance (Table 3 ). These figures underline the high degree of environmental variation in the arid millet-growing zone of NW India, and the consequent difficulties in breeding new cultivars.
More importantly, they indicate why empirical selection for improved grain yield, even in marginal environments, has likely been primarily selection for a higher HI, rather than for greater primary productivity (i.e. biomass), and thus why gains in grain yield have been achieved at the cost of stover yield.

\subsection{Pollinator differences, 1995/1999}

Partitioning total genotype SS into variation due to A-line, pollinator and their interaction resulted in significant MS for all three sources (ANOVA, data not presented). Pollinator was a more important source of variance within genotype than was A-line for HI, grain and stover yields and growth rate (Table 3). Aline and pollinator $\times \mathrm{E}$ interaction MS were also significant for all variables in the ANOVA; but in this case, pollinator $\times \mathrm{E}$ variances exceeded A-line $\times \mathrm{E}$ variances only for $\mathrm{HI}$ and days to flower (Table 3 ).

There was a wide range among individual pollinators in their GCA for various traits (Table 4). All three unimproved pollinators (Nokha Local, BarmerPop and ICMV 94888) had a significant negative GCA for $\mathrm{HI}$ and consequently for grain yield as well. The GCA for HI of two (ERajPop and WRajPop) of the three improved pollinators was positive and significant but did not result in a significant positive GCA for grain yield (Table 4). The third improved pollinator (CZ-IC 311) had a non-significant GCA for both HI and grain yield. The non-landrace pollinator HiTiP

Table 3

Environment, genotype and interaction components of variance and standard errors for biomass, HI, grain and stover yields, days to flowering and vegetative biomass growth rate, from a $7 \times 7$ A-line $\times$ pollinator testcross trial grown in five locations in NW India in 1995 and 1999

\begin{tabular}{lccccccc}
\hline $\begin{array}{l}\text { Source of } \\
\text { variation }\end{array}$ & d.f. $^{\text {a }}$ & Biomass yield & HI & Grain yield & Stover yield & Days to flower & Growth rate \\
\hline Environment (E) & $4(3)$ & $95988 \pm 78775$ & $18.08 \pm 15.43$ & $5440.7 \pm 3872.0$ & $40247 \pm 33051$ & $20.75 \pm 14.78$ & $12.37 \pm 10.15$ \\
Rep within E & 7 & $258 \pm 206$ & $1.28 \pm 0.87$ & $20.0 \pm 20.5$ & $117 \pm 91$ & $0.20 \pm 0.13$ & $0.034 \pm 0.027$ \\
Genotype (G) & 48 & $1044 \pm 1280$ & $11.70 \pm 3.25$ & $52.3 \pm 67.1$ & $924 \pm 703$ & $1.05 \pm 0.35$ & $0.229 \pm 0.209$ \\
A-line (A) & 6 & $396 \pm 1031$ & $2.26 \pm 1.91$ & $0.1 \pm 38.1$ & $378 \pm 571$ & $0.93 \pm 0.60$ & $0.09 \pm 0.16$ \\
Pollinator (P) & 6 & $477 \pm 698$ & $9.58 \pm 6.37$ & $17.4 \pm 41.8$ & $728 \pm 627$ & $0.12 \pm 0.17$ & $0.19 \pm 0.18$ \\
A $\times$ P & 36 & $265 \pm 1205$ & $1.79 \pm 1.24$ & $50.2 \pm 69.4$ & $0 \pm 539$ & $0.13 \pm 0.19$ & $0.00 \pm 0.17$ \\
G $\times$ E & $192(144)$ & $15968 \pm 2173$ & $9.98 \pm 1.94$ & $856.6 \pm 130.1$ & $7954 \pm 1061$ & $2.02 \pm 0.34$ & $2.511 \pm 0.333$ \\
A $\times$ E & $24(18)$ & $2335 \pm 1617$ & $1.18 \pm 1.03$ & $96.2 \pm 75.8$ & $1060 \pm 747$ & $0.03 \pm 0.14$ & $0.29 \pm 0.22$ \\
P $\times$ E & $24(18)$ & $0 \pm 869$ & $2.87 \pm 1.59$ & $52.7 \pm 63.7$ & $200 \pm 470$ & $0.27 \pm 0.21$ & $0.06 \pm 0.15$ \\
A $\times$ P $\times$ E & $144(108)$ & $14378 \pm 2292$ & $6.48 \pm 1.75$ & $714.6 \pm 132.6$ & $6854 \pm 1074$ & $1.81 \pm 0.36$ & $2.20 \pm 0.34$ \\
Residual & $288(228)$ & $4773 \pm 414$ & $13.03 \pm 1.13$ & $714.8 \pm 61.1$ & $2037 \pm 175$ & $2.61 \pm 0.20$ & $0.061 \pm 0.053$ \\
\hline
\end{tabular}

${ }^{\text {a }}$ Figures in parentheses are d.f. for stover yield, biomass yield, HI and growth rate, for which there are only four locations data. 
Table 4

GCA effects of landrace pollinators and male-sterile lines for six traits in pearl millet ${ }^{\mathrm{a}}$

\begin{tabular}{|c|c|c|c|c|c|c|}
\hline \multirow[t]{2}{*}{ Pollinator or A-line } & \multicolumn{6}{|l|}{ GCA for } \\
\hline & $\begin{array}{l}\text { Harvest } \\
\text { index }\end{array}$ & $\begin{array}{l}\text { Grain } \\
\text { yield }\end{array}$ & $\begin{array}{l}\text { Biomass } \\
\text { yield }\end{array}$ & $\begin{array}{l}\text { Stover } \\
\text { yield }\end{array}$ & $\begin{array}{l}\text { Days to } \\
\text { flower }\end{array}$ & $\begin{array}{l}\text { Growth } \\
\text { rate }\end{array}$ \\
\hline \multicolumn{7}{|l|}{ Landrace pollinators } \\
\hline Nokha local & $-2.3^{* *}$ & $-7.0^{\text {*** }}$ & 7.3 & $17.3^{* *}$ & -0.25 & $0.27^{* *}$ \\
\hline BarmerPop & $-3.7^{* *}$ & $-9.5^{* *}$ & $48.5^{* *}$ & $48.5^{* *}$ & $0.42^{* *}$ & $0.79^{* *}$ \\
\hline ICMV 94888 & $-2.3^{* *}$ & $-7.5^{* *}$ & -7.3 & 2.0 & $0.69^{* *}$ & -0.06 \\
\hline CZ-IC 311 & -0.1 & -0.4 & 13.2 & $13.2^{* *}$ & $-0.80^{* *}$ & $0.36^{* *}$ \\
\hline WRajPop & $1.2^{* *}$ & 0.4 & $-32.4^{* *}$ & $-26.8^{* *}$ & 0.20 & $-0.50^{* *}$ \\
\hline ERajPop & $3.7^{* * *}$ & 4.9 & $-39.2^{* *}$ & $-34.5^{* *}$ & $-0.59^{* *}$ & $-0.60^{* *}$ \\
\hline HiTiP & $3.5^{* *}$ & $19.1^{* *}$ & 9.8 & $-19.7^{* *}$ & $0.33^{* *}$ & $-0.34^{* *}$ \\
\hline \multicolumn{7}{|l|}{ A-lines } \\
\hline ICMA 91444 & $-3.14^{* *}$ & 2.1 & $70.4^{* *}$ & $46.1^{* *}$ & $0.32^{*}$ & $0.78^{* *}$ \\
\hline ICMA 89111 & -0.18 & $-5.9^{*}$ & $-19.6^{* * *}$ & $-14.5^{* *}$ & $1.31^{\text {*** }}$ & $-0.37^{* *}$ \\
\hline ICMA 94444 & 0.02 & $-10.5^{* *}$ & $-38.5^{* *}$ & $-17.4^{* *}$ & -0.19 & $-0.31^{* *}$ \\
\hline $841 \mathrm{~A}$ & 0.36 & $6.4^{*}$ & $15.3^{*}$ & 7.5 & $0.49^{* *}$ & 0.07 \\
\hline ICMA 93333 & 0.35 & $9.9^{\text {*** }}$ & $37.4^{* *}$ & $31.8^{* *}$ & 0.14 & $0.63^{* *}$ \\
\hline $843 \mathrm{~A}$ & $0.96^{*}$ & $-6.5^{*}$ & $-31.8^{* *}$ & $-27.8^{* *}$ & $-2.15^{* *}$ & $-0.30^{* * *}$ \\
\hline ICMA 94111 & $1.70^{* *}$ & 4.5 & $-33.2^{* *}$ & $-25.7^{* *}$ & 0.07 & $-0.48^{* * *}$ \\
\hline S.E. & \pm 0.392 & \pm 2.64 & \pm 7.23 & \pm 4.94 & \pm 0.160 & \pm 0.089 \\
\hline LSD (5\%) & 1.086 & 7.31 & 20.02 & 13.68 & 0.443 & 0.246 \\
\hline
\end{tabular}

${ }^{\text {a }}$ Data are from a $7 \times 7$ A-line $\times$ pollinator testcross trial grown in five locations in NW India in 1995 and 1999. Growth rate is calculated as stover dry mass/(flowering +10 days).

${ }^{*} P<0.05$

** $P<0.01$.

had a positive and high GCA for HI, and was the only one of the pollinators to have a significant positive GCA for grain yield (Table 4).

The trend in GCA for both biomass and stover yield was generally opposite to that of $\mathrm{HI}$ and grain yield, but with greater differences among the pollinators. The improved pollinator HiTiP and two of the three improved landrace pollinators, either had a significant negative GCA for both biomass production and stover yield (ERajPop and WRajPop), or for stover yield alone (HiTiP). Two of the unimproved landraces (BarmerPop and Nokha local) had a positive GCA for stover yield, but only BarmerPop had a significant positive GCA for biomass yield as well (Table 4). CZIC 311 and ICMV 94888 were intermediate in the spectrum; neither had a significant GCA for biomass production, but CZ-IC 311 did have a significant positive GCA for stover production. Differences in GCA for biomass appeared to be largely a consequence of differences in GCA for growth rate; all pollinators with a significant GCA for biomass also had a significant GCA for growth rate, with the same sign as the GCA for biomass (Table 4). However, GCA for time to flowering interacted with GCA for growth rate in a number of pollinators, either reinforcing the effect of a significant GCA for growth rate and thus increasing GCA for biomass (BarmerPop and ERajPop) or counteracting it, resulting in a non-significant GCA for biomass (CZ-IC 311 and HiTiP). Therefore both growth rate and maturity need to be considered in increasing hybrid biomass.

\subsection{A-line differences, $1995 / 1999$}

A-line accounted for a greater fraction of genotype variance than did pollinator only for days to flowering; however, A-line was the greater contributor to $\mathrm{G} \times \mathrm{E}$ variance for all traits except $\mathrm{HI}$ and flowering (Table 3 ). The A-lines had a wide range in GCA for both biomass and HI (Table 4). ICMA 94111 and 843A resembled the improved pollinators, in that they had a significant positive GCA for HI, accompanied by a significant negative GCA for biomass. As a consequence of both effects (low biomass productivity and high partitioning 
to the grain), both had a significant negative GCA for stover yield. In addition, ICMA 94111 had a neutral GCA for grain yield and 843A a negative GCA for grain yield; apparently their negative GCA for biomass off set any positive effect on grain yield of a positive GCA for HI (Table 4). In contrast, ICMA 91444 resembled the unimproved landraces in having a highly significant, positive GCA for biomass production, but a significant negative GCA for HI. This resulted in a significant, positive GCA for stover yield, but no effect on grain yield. ICMA 93333 and 841A were intermediate between the above extremes, as they had a significant positive GCA for biomass without a corresponding negative effect on HI. As a consequence, both had a significant positive GCA for grain yield, due to greater partitioning to the grain. In addition, ICMA 93333 had a positive GCA for stover yield, and 841A a neutral GCA for stover yield (Table 4), as their neutral GCA for HI did not offset the positive effects of a positive GCA for biomass, as was the case with the more landrace type A lines. Finally, ICMA 94444 appeared to be very poorly adapted to arid zone environments as it had a significant negative GCA for biomass and, as a consequence, for both grain and stover yields (Table 4). A significant GCA for growth rate was the more common reason for a significant GCA for biomass, than was a significant GCA for flowering in the case of the A-lines (Table 4). This is in contrast to the case of the landrace pollinators, where growth rate and flowering equally affected GCA for biomass. In the case of the individual A-lines, a significant GCA for biomass production was associated with a significant GCA (of the same sign) for growth rate (ICMA 94111, ICMA 93333, ICMA 94444, and ICMA 89111), with a significant GCA of the same sign for flowering (841A), or a significant GCA for both traits (843A and ICMA 91444).

\subsection{A-line $\times$ pollinator interactions, $1995 / 1999$}

A-line $\times$ pollinator interaction MS were highly significant for all traits, as were the A-line $\times$ pollinator $\times$ environment interaction MS (ANOVA, data not presented). The variance due to the A-line $\times$ pollinator interaction was a smaller part of the overall genotype variance than A-line and pollinator variances, for all traits except grain yield, where it exceeded both the Aline and pollinator variances, and in the case of days to flower, where it was similar to the pollinator variance (Table 3). This was in contrast to the case of Aline $\times$ pollinator $\times$ environment interaction variances, where the three-way interaction variances were significantly greater than variances for either Aline $\times \mathrm{E}$ or pollinator $\times \mathrm{E}$ for all traits (Table 3 ). Thus, it is likely that GCA of the parents will account for a significant portion of the mean performance of individual landrace-based TCH for biomass and stover yields, flowering and HI. This suggests that, with a careful selection of parental lines, it should be possible to produce a high frequency of TCH with simultaneous heterosis for both biomass and stover yields. We tested this conclusion, to a limited degree, in the 1996 experiment, which estimated yields and heterosis in a selected set of three A-lines $\times$ three pollinators from the $1995 / 1999$ experiment.

\subsection{Heterosis in TCH 1996}

Total rainfall in 1996 was very favorable, with adequate moisture for grain filling in both locations, due to stored soil moisture from abundant pre-flowering rainfall in Jodhpur and to adequate post-flowering rainfall in Fatehpur (Table 2). Both grain yields (205 and $298 \mathrm{~g} \mathrm{~m}^{-2}$ ) and stover yields (496 and $785 \mathrm{~g} \mathrm{~m}^{-2}$ ) of individual TCH in the 1996 trials were higher than those in the 1995 or 1999 trials (Table 2). These trials thus represented the sort of favorable environments in which heterotic landrace-based TCH would be expected to outperform their landrace pollinators, and in which farmers could capitalize on expenditures for hybrid seed and other inputs. Estimates of heterosis for individual $\mathrm{TCH}$ (\% yield advantage of topcross hybrid over its pollinator) ranged from -19 to $+9 \%$ for biomass and from -5 to $+33 \%$ for $\mathrm{HI}$ (data not reported). Although pollinator MS were significant for both variables, none of the differences in biomass between individual hybrid and pollinator pairs were statistically significant $(P<0.05)$, and only those differences in HI involving WRajPop and its TCH were significant (data not presented). Heterosis for grain yield ranged from -11 to $+17 \%$ and heterosis for stover yield values ranged from -26 to $+6 \%$ (Table 5). Differences among pollinators for both variables, and among A-lines for $\mathrm{HI}$ were significant $(P<0.05)$, but differences in grain and stover yields between individual hybrid and pollinator pairs were 
Table 5

Grain and stover yields of TCH and their pollinators, observed percent heterosis (compared to the pollinator), and predicted percent heterosis for grain and stover yields based on the general combining abilities of parental lines, for testcross combinations of three pollinators and three A-lines ${ }^{\mathrm{a}}$

\begin{tabular}{|c|c|c|c|c|c|c|c|}
\hline \multirow[t]{2}{*}{ A-line } & \multirow[t]{2}{*}{ Pollinator } & \multicolumn{3}{|c|}{ Grain yield } & \multicolumn{3}{|c|}{ Stover yield } \\
\hline & & $\begin{array}{l}\text { Observed } \\
\left(\mathrm{g} \mathrm{m}^{-2}\right)\end{array}$ & $\begin{array}{l}\text { Observed } \\
\text { heterosis }(\%)\end{array}$ & $\begin{array}{l}\text { Predicted } \\
\text { heterosis }(\%)\end{array}$ & $\begin{array}{l}\text { Observed } \\
\left(\mathrm{g} \mathrm{m}^{-2}\right)\end{array}$ & $\begin{array}{l}\text { Observed } \\
\text { heterosis }(\%)\end{array}$ & $\begin{array}{l}\text { Predicted } \\
\text { heterosis }(\%)\end{array}$ \\
\hline \multirow[t]{3}{*}{$843 \mathrm{~A}$} & Nokha local & 227 & 0 & -5 & 785 & +6 & +2 \\
\hline & CZ-IC 311 & 283 & +12 & +8 & 619 & +5 & 0 \\
\hline & WRajPop & 255 & +14 & +9 & 571 & -15 & -21 \\
\hline \multirow[t]{3}{*}{ ICMA 93333} & Nokha local & 203 & -11 & 0 & 762 & +3 & +4 \\
\hline & CZ-IC 311 & 295 & +17 & +12 & 617 & +5 & +2 \\
\hline & WRajPop & 262 & +17 & +14 & 550 & -18 & -19 \\
\hline \multirow[t]{3}{*}{ ICMA 94444} & Nokha local & 227 & 0 & -6 & 762 & +3 & +2 \\
\hline & CZ-IC 311 & 246 & -3 & +7 & 512 & -13 & 0 \\
\hline & WRajPop & 227 & +1 & +8 & 496 & -26 & -20 \\
\hline \multirow[t]{3}{*}{ Pollinator per se } & Nokha local & 227 & & & 741 & & \\
\hline & CZ-IC 311 & 252 & & & 587 & & \\
\hline & WRajPop & 224 & & & 668 & & \\
\hline
\end{tabular}

\footnotetext{
${ }^{\text {a }}$ The yield and observed heterosis data were from replicated trials of TCH and pollinator parents grown in two locations in 1996 . The predicted heterosis data were based on linear regression of observed heterosis values on the general combining abilities of the parents of each individual topcross hybrid, estimated from the 1995/1999 trials (Table 4).
}

again not significant. Nevertheless the data were used for the main purpose for which the trials were conducted-to explore the relationships between parental GCA and heterosis in the hybrids.

Differences among TCH made with individual pollinators generally followed the patterns established in the 1995/1999 trials. For example, TCH made with the unimproved landrace pollinator Nokha local had positive heterosis for stover yield, but a zero or negative heterosis for grain yield, as would be predicted by its GCA for both traits (Table 4). In contrast, TCH made with improved landrace population WRajPop had positive grain yield heterosis but negative stover yield heterosis (Table 5). Two of the three TCH made with the improved pollinator CZ-IC 311, which had positive GCA for both grain and stover yield, had positive heterosis for both traits. The comparison was a bit less predictable in the case of A-lines. TCH made on ICMA 94444 had little or no positive heterosis for either grain and stover yield, as expected from its negative GCA for both traits (Table 4). TCH made on 843A had positive heterosis for grain yield as expected from its GCA for HI, but two of the three had positive heterosis for stover yield as well (Table 5), which was not expected from its GCA for this trait (Table 4). TCH on ICMA 93333 generally had significant positive heterosis for either grain or stover yield, depending largely upon the GCA of the pollinator (Table 5). Only two individual TCH-843A $\times$ CZP-IC 311 and ICMA $93333 \times$ CZP-IC 311 -had positive heterosis for both traits. These two TCH also had the highest grain yields in the trial, but had only average stover yields (Table 5).

\section{Discussion}

\subsection{Genotype vs environmental effects}

Genotype variances were very small compared to those for $\mathrm{E}$ and for $\mathrm{G} \times \mathrm{E}$; $\mathrm{G}$ effects accounted for no more than $2 \%$ of the total variation for biomass, grain and stover yields in the multi-environment 1995/1999 experiment. Only in the case of $\mathrm{HI}$ did $\mathrm{G}$ effects account for a useful percentage $(29 \%)$ of total variation (Table 3). Thus it is much more likely that conventional selection for a high or low HI, i.e. either for grain or for stover yield at the expense of the other, will achieve results, compared to simultaneous selection for both grain and stover yields. Simultaneous 
improvement in both traits for arid zone environments requires a genetic improvement in total biomass yield, which the results of 1995/1999 experiments suggest is not likely to be very effective by conventional, intrapopulation selection. The relatively small genotype variance for biomass, compared to that for environment, and the very small $(<1 \%)$ percentage of total experimental variability for biomass productivity accounted for by genotype indicates that progress from simultaneous selection for both grain and stover yields in such environments will be very difficult to demonstrate.

\subsection{GCA for grain, stover and biomass yields}

GCA for biomass was primarily dependent upon GCA for growth rate, as growth rate accounted for $86 \%$ of the variation in the regression of GCA for biomass on GCAs for growth rate and flowering among both pollinators and A-lines (Table 6). This may have been partly a consequence of limited variation in flowering time among the pollinators and Alines in the experiment, but the opportunity to increase biomass by extending season length (i.e. by a positive GCA for time to flowering) is limited in short season, arid zone environments. Therefore, focusing parental selection on a positive GCA for growth rate is both appropriate and effective.

GCA for grain yield, in contrast, was approximately equally dependent upon GCA for growth rate and GCA for HI, with GCA for growth rate accounting for $32 \%$ of the variation in GCA for grain yield, and GCA for $\mathrm{HI}$ for $39 \%$ (and GCA for flowering for $13 \%$, Table 6). In contrast, GCA for growth rate accounted for $97 \%$ of the variation in GCA for stover yield (Table 6). (This may be largely an auto correlation, however, as growth rate was defined as vegetative (i.e. stover) growth rate only, to avoid biasing growth rate estimates by differences in reproductive sink size, and there was, as noted, limited variation for time to flowering.) Thus, selecting potential topcross hybrid parents for a positive GCA for vegetative growth rate should achieve the objective of exploiting heterosis to improve both grain and stover yields simultaneously.

\subsection{Evaluation of parental lines}

The GCA patterns among the pollinators evaluated in this experiment reflected the degree of conventional genetic improvement they had undergone (Table 1). In general, the improved pollinators had a positive GCA for grain yield, reflecting their history of selection for improved grain yield. The fact that this was achieved by means of selection for HI (as indicted by a positive GCA for HI) however, meant that most had a negative GCA for stover yield, and interestingly, also for vegetative growth rate (Table 4). Why this latter should have been the case is not clear, as at least WRajPop and ERajPop are of arid zone origin. In any case, they will not meet the requirements of arid zone farmers who require well-adapted (i.e. high growth rate) cultivars with both an improved grain yield and an improved stover yield. In contrast, the farmers' current landraces (exemplified by Nokha local and the BarmerPop), possess the adaptation to arid zone conditions (positive GCA for growth rate), but they do not effectively partition dry matter to grain yield, as both have significant negative GCA for HI and grain yield. A possible cause of this is incomplete seed set and/or slow grain growth rate, which is characteristic of many arid zone landraces, and which has been suggested as a mechanism of adaptation to the variable moisture

Table 6

Relationship of GCA for biomass, grain and stover yields and GCA for vegetative growth rate, time to flowering and HI in the 1995/1999 trials $^{\mathrm{a}}$

\begin{tabular}{|c|c|c|c|c|c|c|c|}
\hline \multirow[t]{2}{*}{ Dependent variable } & \multicolumn{2}{|c|}{ Independent variable } & \multicolumn{2}{|c|}{ Independent variable } & \multicolumn{2}{|c|}{ Independent variable } & \multirow[t]{2}{*}{ Model $R^{2}$} \\
\hline & Name & Partial $R^{2}$ & Name & Partial $R^{2}$ & Name & Partial $R^{2}$ & \\
\hline GCA for total biomass & Growth rate & 0.857 & Flowering & 0.030 & & & 0.887 \\
\hline GCA for grain yield & HI & 0.394 & Growth rate & 0.316 & Flowering & 0.126 & 0.836 \\
\hline GCA for stover yield & Growth rate & 0.972 & Flowering & 0.023 & $\mathrm{HI}$ & 0.003 & 0.997 \\
\hline
\end{tabular}

\footnotetext{
${ }^{a}$ Data are partial and model coefficients of determination from stepwise multiple regressions $(N=14)$ involving combined A-line and pollinator GCA for various traits (Table 4).
} 
patterns of arid zone environments (van Oosterom et al., 2003). The exception to this generalization was CZ-IC 311, which looked to be the most promising pollinator by the objectives of this study, as it has a positive combining ability for growth rate and stover yield, without an offsetting negative combining ability for either HI and grain yield (Table 4). It was also the only pollinator to combine a positive GCA for growth rate with a negative GCA for flowering (earlier flowering).

Similar patterns were present among the A-lines tested. The conventional grain type A-lines (ICMA 94111 and 843A) had a significant positive GCA for HI, but were very poorly adapted to arid zone conditions, as indicated by their negative GCA for growth rate, with the consequence that they had a significant negative GCA for biomass, grain and stover yields (Table 4). This is likely a result of a history of selection in, and for, more favorable environments. The intermediate and dual purpose types all had neutral GCA for HI, but varied in their adaptation to the arid zone (both positive and negative GCA for growth rate under arid zone conditions). The level of adaptation to arid zone conditions, as defined by growth rate, almost entirely determined GCA for biomass, stover and grain yields in the dual purpose types; where GCA for biomass was positive, GCA for grain and stover yield was also positive, and vice versa (Table 4). The A-line whose pedigree included two West African arid zone landrace parents, ICMA 91444, had a very high GCA for biomass yield (resulting from a positive GCA for both growth and flowering), resulting in neutral GCA for grain yield despite a negative GCA for HI (Table 4). These patterns strongly underline the need for adaptation to arid zone environments, expressed as a positive GCA for growth rate in such environments, in any A-lines to be used in making TCH for the arid zone. Without a positive GCA for growth rate, A-line GCA for neither grain nor stover yield is likely to be positive, and therefore their TCH will not meet arid zone farmers' needs.

The most promising A-line evaluated was ICMA 93333, which combined a positive GCA for growth rate with a neutral GCA for $\mathrm{HI}$, which resulted in a positive GCA for both grain and stover yields. Two other A-lines had positive GCA for either grain (841A) or stover yield (ICMA 91444), and a neutral GCA for the other trait. Both achieved this through a positive GCA for biomass, 841A by a positive GCA for flowering and ICMA 91444 by a positive GCA for growth rate (Table 4). These two A-lines may have specific uses in making arid zone hybrids, in combination with pollinators that would benefit from an increase in growth duration (e.g. ERajPop) or an improvement in growth rate/adaptation to arid zone conditions (e.g. WRajPop).

\subsection{Prediction of heterosis for stover and grain yields}

The value of assessing GCA of parental lines is related to the ability of the GCA of the parental lines to predict the performance of their test crosses. The variance component analysis of the 1995/1999 data indicted that A-line and pollinator variances were generally larger than the A-line $\times$ pollinator interaction variance (Table 3 ), suggesting that GCA effects were more important than specific combining ability effects for grain and stover yields in the landrace TCH. This was borne out in the 1996 experiment, as GCA of parental lines proved to be a useful basis for predicting trends in actual heterosis in their TCH (Table 5). Regression-predicted heterosis values, based on parental GCA for grain yield, identified the positive heterosis for grain yield in the crosses of both CZIC 311 and WRajPop with 843A and with ICMA 93333 (Table 5). The predicted heterosis did overestimate the observed heterosis for grain yield in the crosses of the same pollinators to ICMA 94444, however. Similarly, the predicted heterosis values correctly identified the marked negative heterosis for stover yield in all of the WRajPop TCH and the positive stover heterosis in the case of all of the Nokha Local TCH (Table 5). The two parents identified as most likely to produce TCH with heterosis for both grain and stover yields from their GCA (ICMA 93333 and CZ-IC 311) produced a TCH with $17 \%$ heterosis for grain yield and 5\% heterosis for stover yield (Table 5). GCA for grain and stover yields thus appear to be useful in identifying parental lines which will produce landrace-based TCH for the arid zone with positive heterosis for both grain and stover yields.

We examined this conclusion further by running stepwise regressions of heterosis for both grain and stover yields in 1996 against parental GCA for growth rate and $\mathrm{HI}$ (as growth rates seemed to be the major 
Table 7

Relationship of heterosis (over pollinator parent) for grain and stover yield in the 1996 trials to parental GCA for grain yield, stover yield, vegetative growth rate and $\mathrm{HI}^{\mathrm{a}}$

\begin{tabular}{|c|c|c|c|c|c|c|c|c|c|}
\hline \multirow[t]{2}{*}{ Dependent variable } & \multicolumn{4}{|l|}{ A-line GCA } & \multicolumn{4}{|c|}{ Pollinator GCA } & \multirow[t]{2}{*}{ Model $R^{2}$} \\
\hline & Variable & Partial $R^{2}$ & Variable & Partial $R^{2}$ & Variable & Partial $R^{2}$ & Variable & Partial $R^{2}$ & \\
\hline Grain yield heterosis & Grain yield & 0.065 & & & Grain yield & 0.285 & & & 0.349 \\
\hline Grain yield heterosis & Growth rate & 0.062 & HI & 0.134 & Growth rate & $\mathrm{NS}^{\mathrm{b}}$ & HI & 0.423 & 0.619 \\
\hline Stover yield heterosis & Stover yield & NS & & & Stover yield & 0.755 & & & 0.755 \\
\hline Stover yield heterosis & Growth rate & 0.039 & HI & -0.120 & Growth rate & 0.689 & HI & +0.076 & 0.923 \\
\hline
\end{tabular}

${ }^{a}$ Data are partial and model coefficients of determination from stepwise multiple regressions $(N=9)$ of yield heterosis (Table 5) as dependent variables, on A-line and pollinator GCA for various traits (Table 4) as independent variables.

${ }^{\mathrm{b}}$ Variable not selected in the stepwise regression analysis $(P>0.50)$.

determinant of GCA for grain and stover yields in the $1995 / 1999$ experiments) and compared this with the stepwise regression against parental GCA for grain and stover yields themselves. Despite the ability of parental GCA for grain and stover yield to identify the individual TCH with the highest grain and stover heterosis in 1996 (Table 5), parental GCA for grain and stover yield accounted for only $35 \%$ of the variation in measured heterosis for grain yield (Table 7). The situation was more promising for stover yield, however, as parental GCA for stover yield accounted for $76 \%$ of the variation in heterosis for stover (Table 7). Not surprisingly, given that heterosis was expressed as a percentage of pollinator yield, pollinator GCA explained the majority of the variation in heterosis for both grain yield and stover yield. When heterosis was regressed on parental GCA for growth rate and HI, the fraction of the variation in heterosis accounted for by parental GCA increased to $62 \%$ for grain yield and to $92 \%$ for stover yield (Table 7 ). GCA for HI of both A-line and pollinator contributed to heterosis for grain yield (defined as partial $R^{2}>0.10$ ), but only the pollinator GCA effect approached significance $(P<0.07)$. A-line GCA for $\mathrm{HI}$ and pollinator GCA for growth rate both contributed to heterosis for stover yield, with both effects being marginally significant $(P<0.06$ and $P<0.05$, respectively). The 1996 trial contained too few hybrids and was grown in too few environments to draw definitive conclusions from the results. However, the trends evident in the results do support a more definitive test of the original hypotheses that selecting both A-lines and landracebased pollinators on the basis of a positive GCA for growth rate and a neutral (or non-negative) GCA for HI should produce TCH with positive heterosis for both grain and stover yields. It is important however, that the evaluations of both parental GCA and heterosis be carried out in arid zone environments, to assure that selected parental lines are well adapted to the common stresses of these environments.

Although the results support the conclusion that the selection of parental lines on the basis of their GCA for growth rate and $\mathrm{HI}$ should result in a higher proportion of TCH with heterosis for both grain and stover yield, the variance components analysis of the 1995/1999 trial suggests that the stability of performance of individual test crosses may be less predictable. This is because, in contrast to the case of genotype variance, specific combining ability effects (A-line $\times$ pollinator) were a greater component of the $\mathrm{G} \times \mathrm{E}$ variance than were either A-line or pollinator effects (Table 3 ). If this is the case, then experimental TCH made from selected parents must be evaluated in enough representative arid zone environments, to identify those specific combinations with minimal $\mathrm{G} \times \mathrm{E}$ variance or maximum yield stability over representative test environments.

\section{Conclusions}

To improve productivity and maintain sustainability of traditional pearl millet-based farming systems in arid zones, farmers require an increase in both grain and stover production, without compromising the yield stability that is required for adaptation to these zones. Landrace-based TCH may be able to meet these requirements, if it is possible to increase grain yield through exploiting heterosis for biomass, rather than through increased partitioning of dry matter to the 
grain. We hypothesized that this could be achieved by combining landrace-based pollinators with a significant positive GCA for growth rate/biomass productivity, with A-lines with a non-negative GCA for both grain and stover production.

Combining ability estimates on a set of landracebased pollinators with differing breeding histories demonstrated that previous selection has resulted in an increased GCA for HI and grain yield, but at the expense of GCA for stover yield. Similarly, grain, intermediate and dual purpose male-sterile parents differed in the GCA for grain and stover yield, according to the purpose for which they were selected. From these combining ability estimates, we identified pollinators and seed parents that met the criteria cited above. A limited evaluation of $\mathrm{TCH}$, based on a subset of parental lines, showed that (1) parental GCA for grain and stover yield was a useful predictor of heterosis for these traits, and (2) the combination of a positive GCA for growth rate and a neutral GCA for $\mathrm{HI}$ did produce $\mathrm{TCH}$ with a positive heterosis for both grain and stover yield.

\section{Acknowledgements}

The authors would like to acknowledge Dr. E. Weltzien R. for supplying seed of the various pollinators used in the experiment and for assistance in supervising the 1995 and 1996 experiments, and Messrs. Mohammed Bashir Ahmed and D.V. Chandra Mohan Rao for excellent technical assistance in Jodhpur and Fatehpur, respectively.

\section{References}

Agarwal, R.K., Kumar, P., Power, J.F., 1997. Use of crop residue and manure to conserve water and enhance nutrient availability and pearl millet yield in an arid tropical region. Soil Till. Res. 41, 43-51.

Austin, R.B., Ford, M.A., Morgan, C.L., Yeoman, D., 1993. Old and modern wheat cultivars compared on the Broadbalk wheat experiment. Eur. J. Agron. 2, 141-147.

Bidinger, F.R., Hash, C.T., 2003. Pearl millet. In: Nguyen, H., Blum, A. (Eds.), Integration of Physiology and Molecular Biology in Plant Breeding. Marcel Dekker, New York.

Bidinger, F.R., Weltzien R., E., Mahalakshmi, V., Singh, S.D., Rao, K.P., 1994. Evaluation of landrace topcross hybrids of pearl millet for arid zone environments. Euphytica 76, 215-226.
Bramel-Cox, P.J., Andrews, D.J., Bidinger, F.R., Frey, K.J., 1984. A rapid method of evaluating growth rate in pearl millet and its weedy and wild relatives. Crop Sci. 24, 1187-1191.

Burton, G.W., 1968. Epistasis in pearl millet forage hybrids. Crop Sci. 8, 365-368.

Ceccarelli, S., 1994. Specific adaptation and breeding for marginal conditions. Euphytica 77, 205-219.

Gupta, S.K., Phul, P.S., 1981. Analysis of quantitative genetic variation from generation means on pearl millet. Zeitschrift fur Pflanzen. 89, 319-329.

Hanna, W.W., Gupta, S.K., 1999. Breeding for forage. In: Khairwal, I.S., Rai, K.N., Andrews, D.J., Harinarayana, G. (Eds.), Pearl Millet Breeding. Oxford/IBH, New Delhi, India, pp. 303-316.

Kelley, T.G., Parthasarathy Rao, P., Weltzien R., E., Purohit, M.L., 1996. Adoption of improved cultivars of pearl millet in an arid environment: straw field and quality considerations in western Rajasthan. Exp. Agric. 32, 161-172.

Kempthorne, O., 1957. An Introduction to Genetic Statistics. Wiley, New York.

Lynch, P.J., Rattunde, E.W., Frey, K.J., 1995. Inheritance of vegetative growth index and related traits in pearl millet. Crop Sci. 35, 394-396.

Rattunde, H.F., Witcombe, J.R., 1993. Recurrent selection for increased grain yield and resistance to downy mildew. Plant Breed. 110, 63-72.

Rattunde, H.F., Singh, P., Witcombe, J.R., 1989. Feasibility of mass selection in pearl millet. Crop Sci. 29, 1423-1427.

Sastri, A.S.R.A.S., Ramana Rao, B.S., Rama Krishna, Y.S., Rao, G.G.S.N., 1982. Agricultural droughts and crop production in the Indian arid zone. Arch. Meteorol. Geophys. Bioclimatol. 31, 405-411.

Talukdar, B.S., Singh, S.D., Prakash Babu, P.P., 1996. Prospects of topcross hybrids in increasing and stabilizing grain yield in pearl millet. Crop Improve. 23, 146-150.

van Oosterom, E.J., Whitaker, M.L., Weltzien R., E., 1996. Integrating genotype by environment interaction analysis, characterization of drought patterns, and farmer preferences to identify adaptive plant traits in pearl millet. In: Cooper, M., Hammer, G.L. (Eds.), Plant Adaptation and Crop Improvement. CAB International, Wallingford, UK, pp. 383-402.

van Oosterom, E.J., Bidinger, F.R., Weltzien R., E., 2003. A yield architecture framework to explain pearl millet adaptation to environmental stress. Field Crops Res. 80, 33-56.

Virk, D.S., 1988. Biometrical analysis in pearl millet-a review. Crop Improve. 15, 1-29.

Yadav, O.P., Weltzien R., E., 1998. New pearl millet populations for Rajasthan, India. Integrated Systems Project Report Series No. 10. International Crops Research Institute for the SemiArid Tropics, Patancheru, India, 88 pp.

Yadav, O.P., Weltzien R., E., 2000. Differential response of pearl millet landrace-based populations and high yielding varieties in contrasting environments. Ann. Arid Zone 39, 39-45.

Yadav, O.P., Weltzien R., E., Bidinger, F.R., Mahalakshmi, V., 2000. Heterosis in landrace-based topcross hybrids of pearl millet across arid environments. Euphytica 112, 285-295. 